\title{
The Influence of Electric-Arc-Furnace Input Feeds on its Electrical Energy Consumption
}

\author{
Vito Logar ${ }^{1}\left[\right.$ [ Igor Škrjanc ${ }^{1}$ (1)
}

Received: 5 March 2021 / Accepted: 4 June 2021 / Published online: 6 July 2021

(c) The Author(s) 2021

\begin{abstract}
Operation of the electric arc furnaces (EAFs) is a subject to consider fluctuations in terms of its key performance indicators, such as the electrical energy consumption (EEC), tap-to-tap time, steel yield, and others. In this paper, a more detailed analysis of the electric arc furnace data is performed, investigating its EEC. It is well known that the EEC is affected by the weight and the type of charged scrap, the operational delays, and the tapping temperature. On the other hand, one can also deduce that the feeds, such as the carbon and the oxygen, could also affect the EEC, due to their role in redox equations and impact to the bath energy balance. Therefore, special attention is devoted to the analysis of the carbon-to-oxygen ratio during the electric arc furnace operation and the consequent influence of the oxygen availability on the EEC. Statistical analysis of more than 2500 heats of data, which were clustered according to the produced steel grade and the charged scrap mixture, has revealed that besides the beforementioned factors, fluctuations in EEC could appear also due to different amounts of added carbon and oxygen. Since the furnace operators usually rely on predefined guidelines and their own experience when actuating the furnace, a simplistic statistical approach can be used to reveal some of the weaknesses in the control routines, which can be used as a starting point to improve their actuation, leading to decreased energy consumption.
\end{abstract}

The contributing editor for this article was Veena Sahajwalla.

Vito Logar

vito.logar@fe.uni-lj.si

Igor Škrjanc

igor.skrjanc@fe.uni-lj.si

1 Laboratory of Control Systems and Cybernetics, Faculty of Electrical Engineering, University of Ljubljana, Tržaška 25, 1000 Ljubljana, Slovenia 


\section{Graphical Abstract}

\section{The influence of EAF input feeds on its electrical energy consumption}
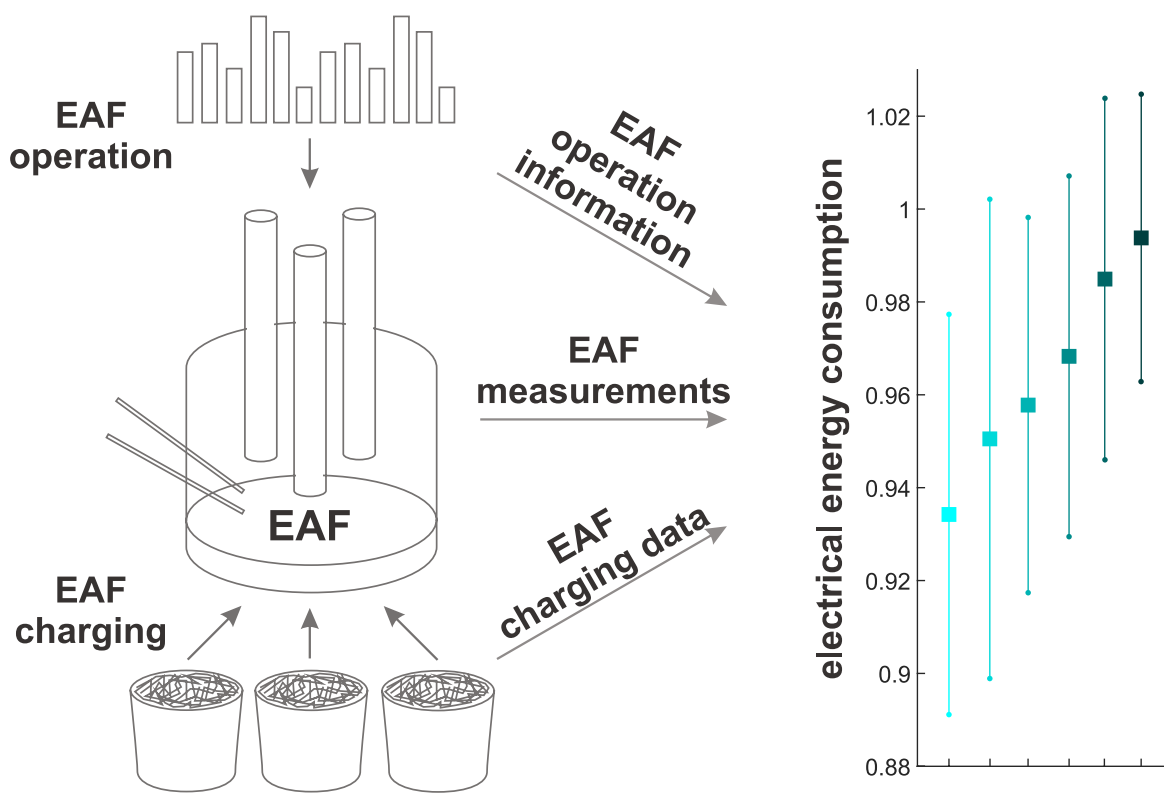

Keywords Data analysis · EAF $\cdot$ Electrical energy consumption $\cdot$ Influential factors $\cdot$ Process improvement

\section{Introduction}

In the steel making industry, electric arc furnaces (EAFs) are considered as one of the systems with the largest consumption of electrical energy. Modern EAFs, besides other forms of energy, such as gas burners and oxygen additions, in average consume from 400 to $500 \mathrm{kWh}$ of electrical energy per ton of steel [1]. In order to reach such consumptions, several new technologies were introduced in the past decades, such as off gas and slag heat recovery [2-4], CO post-combustion, oxy-fuel burners [5], oxygen addition [6], high power transformers [7], bottom stirring, and many others. Furthermore, several approaches to enhance or optimize the EAF control or its subsidiary systems have been proposed [8-12], with the goal of lowering the production costs of an EAF. In this regard, electrical energy consumption (EEC) has also been a subject of considerate attention.

Several studies on prediction of the EAFs' EEC using different modeling approaches have been performed [13-16], based either on commercial software, regression methods, or different artificial-intelligence approaches. The methods in such studies usually focus on calculating a reliable EEC forecast and not as much on the factors that cause the fluctuations in EECs, or on the ideas and solutions that would lead to lower EEC.
When analyzing an EAF from the energy point of view, two groups of factors that influence the EEC, can be formed, i.e., technology related, and operation related. Technology-related factors are known and comprise different auxiliary EAF systems mentioned in the previous paragraph, which lower the overall EEC. Their influence on EAFs' energy balance was analyzed and presented in many publications and is validated in the industrial environments. On the other hand, the influence of operationrelated factors, such as the charged scrap types and weight, additions, and operational delays, to EAF's EEC is not examined as thoroughly and not as evident as the first category. Only a few studies exist, trying to explain the above factors to the EAF EEC, which are reviewed hereinafter.

According to the statistical approach proposed by Köhle [17] and later revised and extended by Pfeifer and Kirschen [18], approximate EEC can be estimated by taking into the account the following factors: charged scrap weight, furnace tapping weight, charged slag formers weights, charged DRI and HBI weight, charged shredder weight, amount of hot heel, tapping temperature, power-on and power-off time, added gas, added oxygen, and energy losses (if measured). As can be seen in the publication, except the shredded scrap, no other types of scrap are separately quantified in the proposed equation. Derived from the publication, the absolute estimation error in EEC reaches to more than $100 \mathrm{kWh} / \mathrm{ton}$. A similar study, yet 
investigating stainless steels instead of carbon, focusing also on the chemical composition of the scrap, and using artificial neural networks, was performed by Gajić et al. [19].

As shown by Matino et al. [20], besides the shredded scrap, an important role in decreasing EEC is also played by high-quality scraps, such as sheet metal. The study revealed that significant decrease in EEC and a higher metallic yield can be achieved when using higher quality scrap, as a consequence of easier melting, better chemical balance, and improved slag foaming. Similar observations were also obtained by Haupt et al. [21], quantifying electrical demand between lower and higher quality scraps, where the difference in estimated electricity demand between them can reach up to $38 \%$. The effect of scrap mix and its optimization in terms of EEC was studied also by Sandberg [22]. A different study, examining the effect of the added chemical energy to EEC was performed by Pesamosca and Patrizio [23]. As has been shown, the relation between the added chemical energy and the change in EEC in non-linear, meaning that a linear increase in added chemical energy does not mean linear decrease in the EEC or other key performance indicators (KPIs) of the EAF.

As can be derived from these studies, the impact of charged scrap or added chemical energy is evident; however, it is hard to accurately determine and explain the differences in EECs between similarly charged heats. Consequently, exact prediction of the endpoint EEC per ton of steel is difficult due to numerous reasons, such as statistical approach (neglecting dynamic process properties), non-linear relations between influential factors and EEC, and due to the differences in installed EAF technology. Nonetheless, a good use of statistical methodology can be made to obtain a list of factors, which have a significant influence on the EAF's EEC, and determine their approximate influence on the EEC in percent (\%). In our opinion, besides all the previously mentioned factors, the ratio between the injected carbon and lanced oxygen also plays an important role in the overall EAF EEC and needs to be properly balanced in order not to worsen the EAF's KPIs.

Thus, the paper examines the effects of charged scrap types, scrap weight, tapping temperature, operational delays, and the amounts of injected carbon and lanced oxygen, to the EAF's EEC. As presented in the literature review, some of the factors have already been studied but are analyzed also in this paper to confirm or rule out their relation to the EEC. Furthermore, the paper also addresses a more in-depth analysis of the fluctuations in EECs, which occur among similarly charged heats, which are intended to produce equal steel grades and have the same tapping-temperature intervals. In this respect, a more detailed analysis of the ratio between added carbon and oxygen is performed to check whether any obvious relations between EECs, carbon addition, and oxygen lancing can be found.

The aim of the study is twofold, first to determine the list of influential factors, affecting the EAFs EEC, and second, to propose a relatively simple methodology based on statistical data manipulation and clustering that can be used to obtain some guidelines in the EAFs efficiency in terms of EEC prior to processing a certain heat, and/or to determine a more optimal charging patterns and EAF actuation.

\section{Methodology}

\section{EAF}

For the needs of this study, operational data of a modern, 100-ton AC EAF is used. The furnace is equipped with an 85 MVA, 3-phase AC transformer, two oxygen injectors, and one carbon injector. No CO post-combustion, gas burners, or bottom stirring is used. The EAF is used to produce three main steel targets in terms of their characteristics, i.e., (a) electrical steels, (b) structural steels, and (c) special steels, which differ in terms of their prescribed endpoint quality. The studied EAF and some of its characteristics can be schematically represented by Fig. 1 .

\section{Measurements}

The measurements used in this study were obtained during a normal EAF operation, i.e., no staged or predefined experiments were performed. The reason not to stage the experiments is in the selection of the selected methodology, classifying the heats according to influential factors and charging, and thus, eliminating their intertwined influence as much as possible. All processed heats follow a threebucket charging pattern. In order to perform the analysis, all important measurements (online/continuous or endpoint) are accessible, such as the charged scrap type and weight, power-on and power-off times, EEC, oxygen consumption, carbon consumption, and endpoint steel composition.

Heats with incomplete measurements were discarded. In order to obtain reliable results and to eliminate the effect of the hot heel as much as possible, only the heats with 95-100 tons of charged scrap are used, leading to approximately 2500 complete heat measurements, which are used to perform the analysis.

Due to the non-disclosure agreement (NDA) between the Faculty of electrical engineering, University of Ljubljana and the steel producer, all presented data, except the charging weights and temperatures, are normalized in order to 


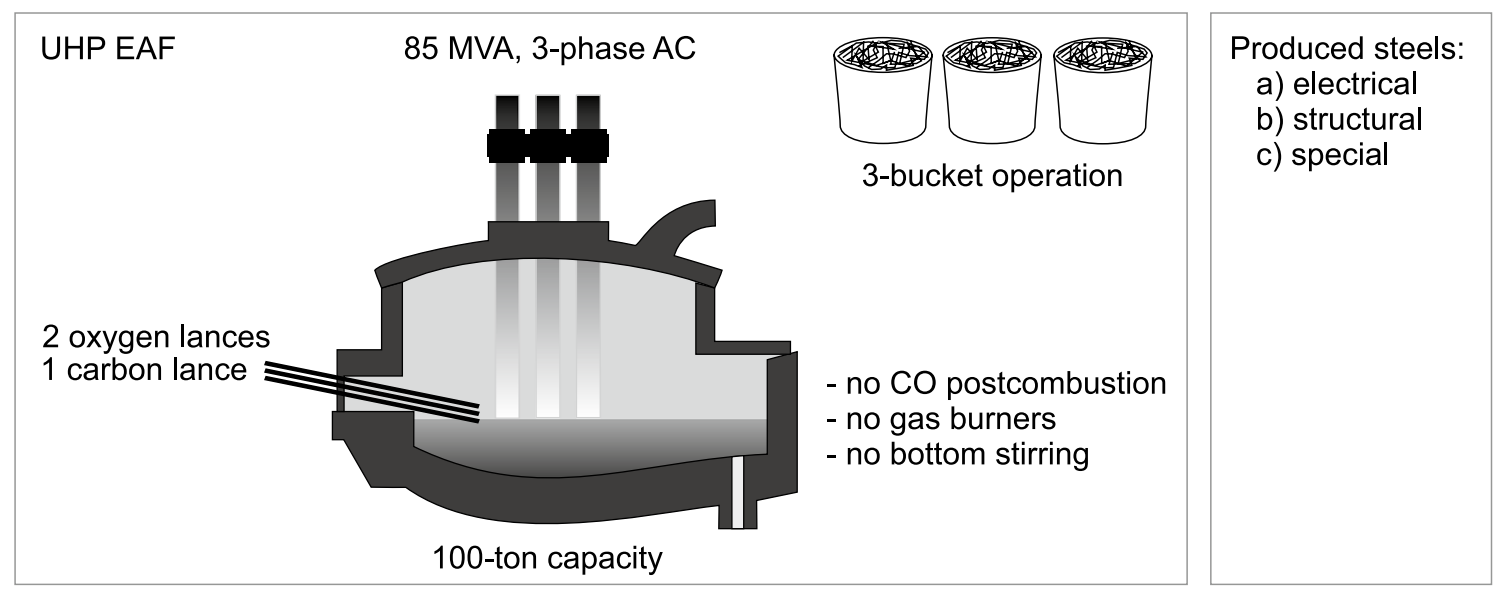

Fig. 1 Schematical representation and the characteristics of the studied EAF

conceal the actual values of the production data. Nevertheless, all important findings and results are not affected by this modification.

\section{Scrap Types}

The studied EAF is charged with 4 main scrap types, i.e., pig iron, heavy melting scrap (internal solidified scrap, internal crops, industrial scrap, tundish leftovers etc.), shredded scrap, and sheet metal or other easy-melting scrap. Charged scrap types differ in terms of specific weight and size, estimated melting yield, and chemical composition.

\section{Used Methods}

The implemented calculations and the results obtained are based on basic statistical methodology, i.e., population means and standard deviations, moving averages, Welch's $t$ tests, and multilevel hierarchical discrete wavelet transform (DWT) clustering. The sequence of data analysis is performed as follows. First, the influence of operational delays on EEC, followed by the influence of tapping temperature on EEC, is performed. Next, the data are split into three groups, according to the three produced steel grades. The heats in each group are then clustered into two clusters using a multilevel hierarchical DWT-clustering method, according to the types and weights of the charged scrap. For each cluster, an average EEC and its standard deviation are calculated. The significance of differences between populations is tested by the Welch unequal variance $t$ test. Furthermore, the effect of hot heel on EECs in all clusters is checked. Finally, the heats in each cluster are grouped to those with higher and those with lower EEC. For each group, an average carbon and oxygen addition are calculated, together with an approximate oxygen availability, trying to explain one of the possible reasons for EEC fluctuations between the heats in the same clusters.

Statistical analysis is in most cases performed on the level of each steel grade, eliminating the possibility of false results due to different endpoint demands, which require alterations in EAF actuation. Moreover, where necessary, initial and endpoint chemical compositions are used in calculations to eliminate the possibility of misleading results due to false chemical estimations. Furthermore, the analysis is performed using the heats with minimal operational delays (except where the influence of the delays on EEC is shown), since their influence on EEC is not negligible as shown in results section. Also, where necessary, i.e., when calculating the $\mathrm{C}$-to- $\mathrm{O}_{2}$ ratios, heats with similar tapping-temperature range, i.e., from 1680 to $1720^{\circ} \mathrm{C}$, are used.

\section{Results}

\section{The Influence of Operational Delays on EEC}

As proposed in $[17,18]$, operational delays should play an important role in overall EAF EEC. To examine whether operational delays significantly influence the EEC of the studied EAF, moving average values of the EEC were calculated as a dependent variable of increasing power-off time. Moving average interval was set to $1 / 4$ of the total data length. All other factors, such as the charged scrap types and weights, and the charged additions are not considered. The results are shown in Fig. 2.

As can be seen in Fig. 2, operational delays significantly affect the EAFs EEC. The difference in EECs between a normal power-off of $5 \mathrm{~min}$ and a significant power-off of $30 \mathrm{~min}$ can reach up to $3 \%$ in average. Considering an average EEC of a typical EAF, e.g., $450 \mathrm{kWh} / \mathrm{ton}$, this can lead up to approximately $13.5 \mathrm{kWh} /$ ton difference. In all three cases, 
Fig. 2 The influence of poweroff times on the EEC for each steel grade. a Electrical steels; b structural steels; c special steels. Number of heats for each steel grade: electrical $=1068$, structural $=1112$, special $=331$, all $=2511$

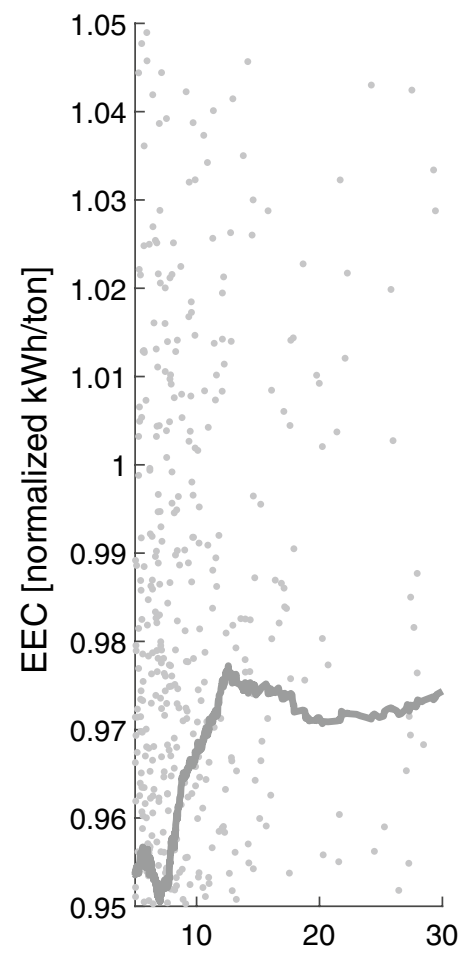

(a)

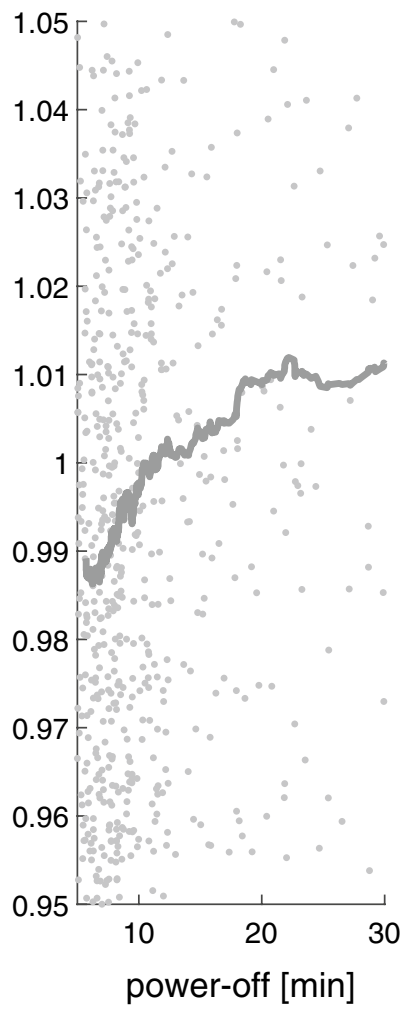

(b)

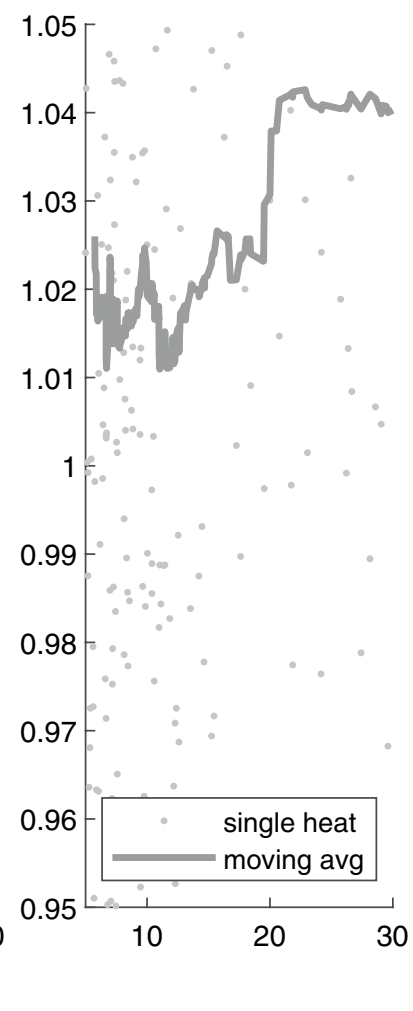

(c) the EEC is gradually increasing with longer power-off times, which confirms the relation between the EEC and the operational delays. Also visible in Fig. 2, the relation between the power-off times and the EEC is not linear as proposed in $[17,18]$. According to Fig. 2, the highest increase in EEC appears from 7 to $20 \mathrm{~min}$ and, afterwards, stays approximately stagnant, which is most likely an estimation error due to low number of samples (heats) with such delays.

The influence of operational delays to EEC can also be presented in Fig. 3, showing the mean EEC values for each steel grade for all power-off times, power-off times shorter than $10 \mathrm{~min}$, and power-off times longer than $10 \mathrm{~min}$.

As can be seen in Fig. 3, the power-off times longer than 10 min have the greatest influence on the EEC, as their distance from the mean EECs is much higher than the distance between the mean EECs and the EECs of heats with poweroffs shorter than $10 \mathrm{~min}$.

According to Figs. 2 and 3, it can be concluded that operational delays have a significant effect on the EEC. Also, as shown, the relation between them is non-linear.

\section{The Influence of the Tapping Temperature on the EEC}

As proposed in $[17,18]$, tapping temperature should play an important role in overall EAF EEC. To examine whether tapping temperature influences the EEC, a simple analysis is performed, i.e., obtaining the EECs at the time of bath temperature measurement. All other factors, such as charged scrap types and weights, carbon and oxygen addition, and targets are not considered. Heats with power-off times smaller than $10 \mathrm{~min}$ are considered. A linear regression of the EECs is performed to examine whether there is any relation between tapping temperature and EEC.

Figure 4 shows the relation between the tapping temperatures and the corresponding EECs, together with the performed linear regression.

As can be seen in Fig. 4, the relation between the tapping temperature and the EEC exists. Higher tapping temperatures lead to higher EEC, which is expected as more energy is needed to heat the bath to a higher temperature. The difference in EECs between 1680 and $1750{ }^{\circ} \mathrm{C}$ reaches in average up to $2 \%$. Considering an average EEC of a typical EAF, e.g., $450 \mathrm{kWh} /$ ton, this can lead up to $9 \mathrm{kWh} /$ ton difference.

\section{The Influence of Charged Scrap Types and Weight on EEC}

As proposed in [18, 19], charging the EAF with larger amount of higher quality and easier melting scraps, such as shredder and sheet metal, leads to decrease in EEC. To examine whether this is valid also for the studied EAF, the 
Fig. 3 Mean values of the EEC for each steel grade and three different power-off time scenarios (all power-off times, power-off times $<10 \mathrm{~min}$, power-off times $>10 \mathrm{~min}$ ). a Electrical steels; $\mathbf{b}$ structural steels; c special steels

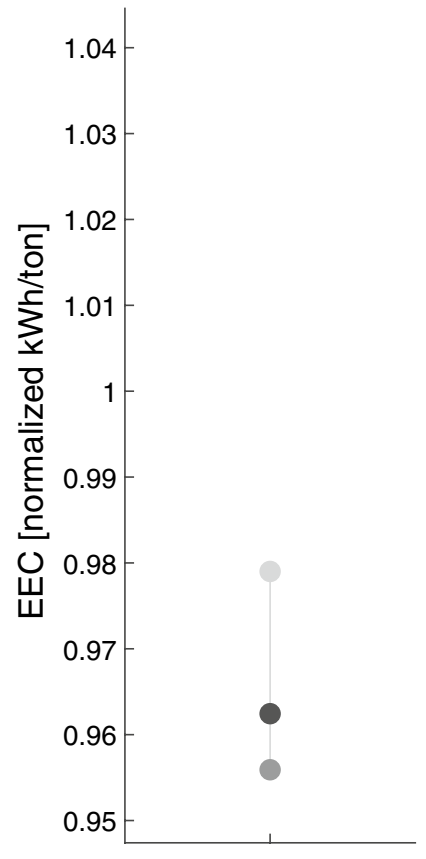

(a)

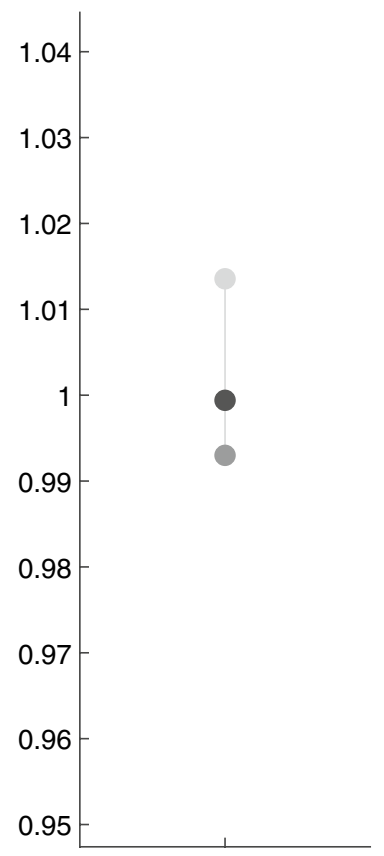

(b)

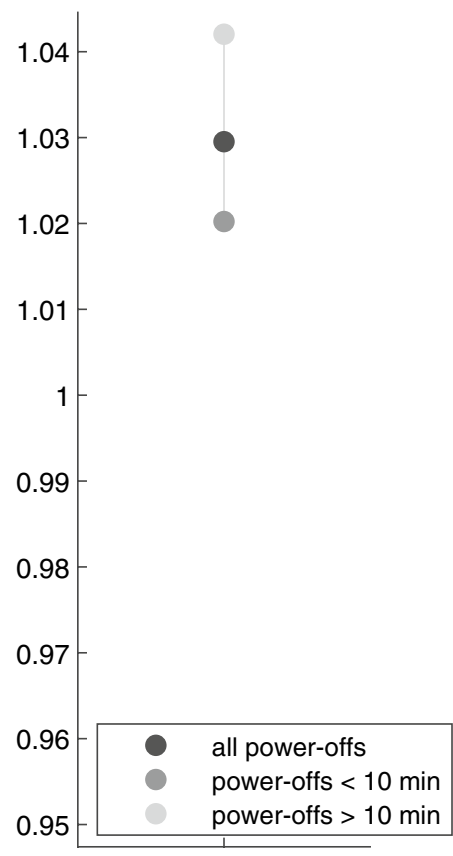

(c)

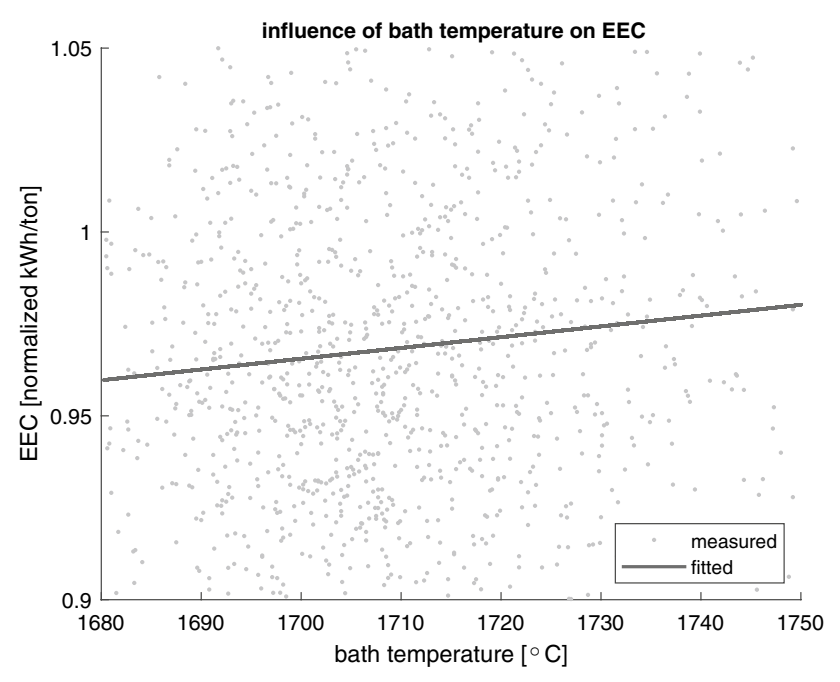

Fig. 4 Relation between tapping temperature and EEC with fitted linear regression

heats for each steel grade are classified into two clusters by using a 1-dimensional multisignal hierarchical clustering using a DWT, according to the charging patterns. The first clusters contain the heats where the EAF was charged with more sheet metal and less heavy scrap, while the second clusters contain the heats where the EAF was charged with less sheet metal and more heavy scrap. The weights of all three baskets are summed together to perform the analysis. EEC means and standard deviations were calculated for each cluster, and Welch's $t$ test was performed to test the hypothesis of equal means. Heats with power-off times lower than $10 \mathrm{~min}$ and in a $1680-1720^{\circ} \mathrm{C}$ tapping-temperature range were used to perform the analysis. Figure 5 shows the charging patterns for each of the clusters.

As can be seen in Fig. 5, in all three cases, the clustered heats exhibit the same charging pattern. Clusters 1 contain heats where a smaller amount of heavy scrap and more sheet metal was charged, while clusters 2 contain heats where a greater amount of heavy scrap and less sheet metal was charged. Differences between other types, such as pig iron and shredder, are much smaller and therefore, should not influence the studied EEC. Furthermore, comparison of the EECs between clusters 1 and 2 was performed for each target. Figure 6 shows the differences between the clusters in terms of the EEC.

As can be seen in Fig. 6, in all three cases, the EEC for clusters 1 is visibly lower than the EEC for clusters 2, which can be attributed to differences in charging, i.e., more heavy scrap and less sheet metal leads to higher overall EEC.

The differences between clusters for each steel target in EEC are also presented in Table 1, showing mean values and standard deviations (SDs) for EECs within each cluster, as well as the results of $t$ and $p$ (significance) values of the Welch unequal variance $t$ test.

As can be seen in Table 1, differences in EECs between clusters 1 and 2 for electrical and structural steel grades are significantly different according to the Welch $t$ test. Low $p$-values denote that mean EEC values of the clusters are significantly different and did not occur by chance. In this 
Fig. 5 Means and standard deviations of the charged scrap type weights for two clusters in terms of charging patterns (cluster 1: less heavy scrap, more sheet metal; cluster 2: more heavy scrap, less sheet metal). a Electrical steels; b structural steels; c special steels

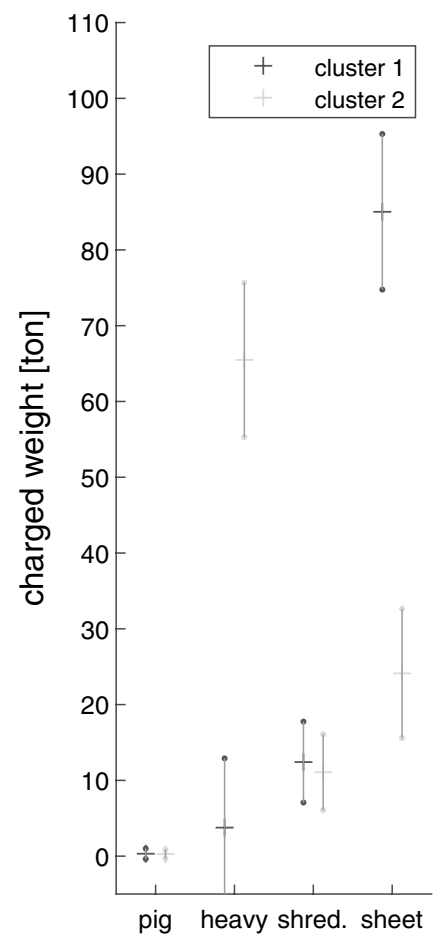

(a)

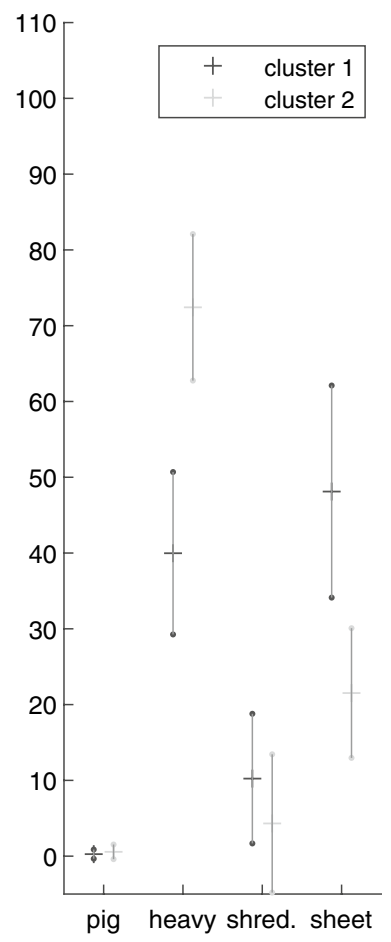

(b)

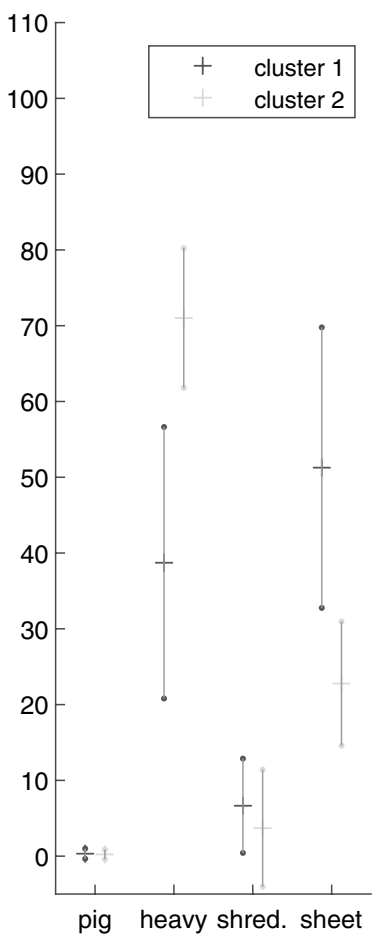

(c)
Fig. 6 Means and standard deviations of EEC for clustered heats with different charging patterns. a Electrical steels; b structural steels; c special steels

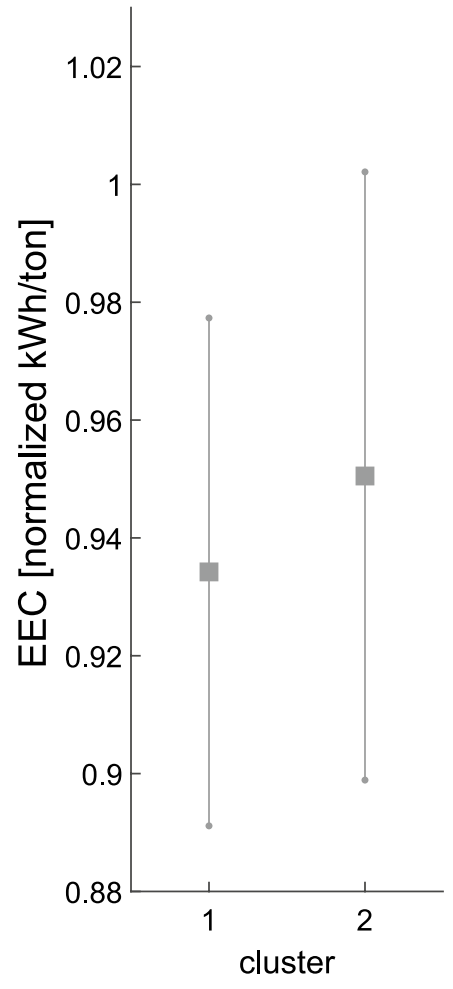

(a)

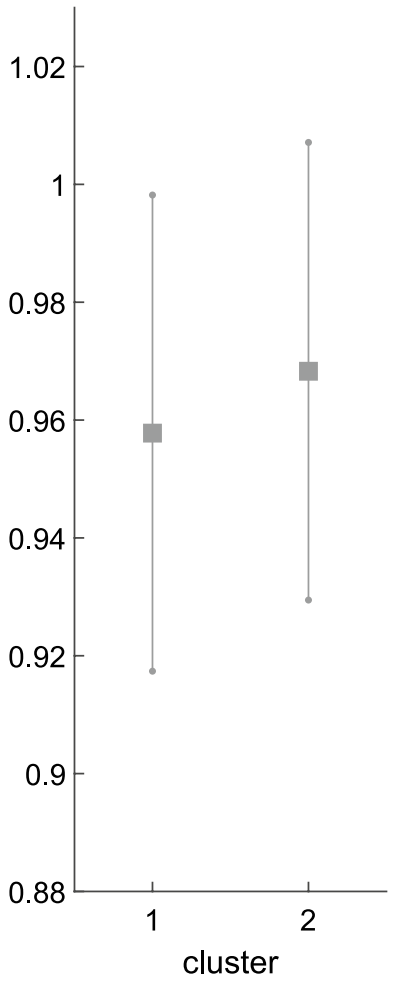

(b)

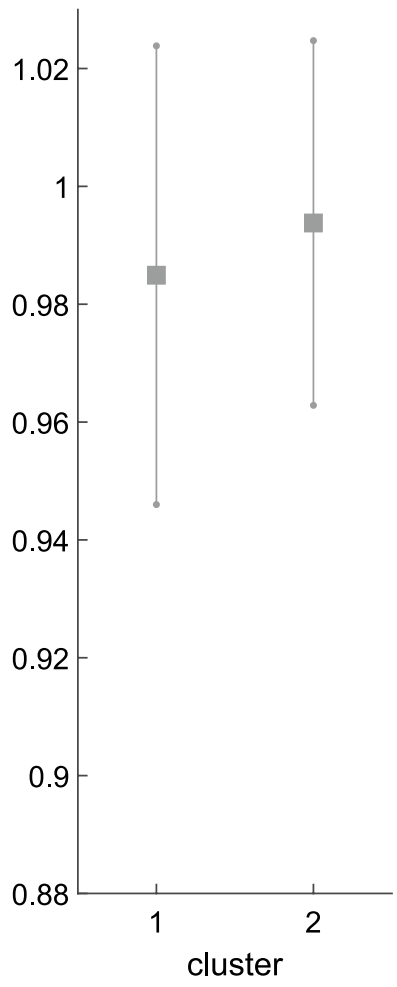

(c) 
Table 1 Means, SD, and the results of the Welch $t$ test for EECs for all clusters

\begin{tabular}{|c|c|c|c|c|c|c|}
\hline \multirow{2}{*}{$\begin{array}{l}\text { Target } \\
\text { Cluster }\end{array}$} & \multicolumn{2}{|l|}{ Electrical } & \multicolumn{2}{|l|}{ Structural } & \multicolumn{2}{|l|}{ Special } \\
\hline & 1 & 2 & 1 & 2 & 1 & 2 \\
\hline Mean EEC & 0.934 & 0.951 & 0.957 & 0.968 & 0.985 & 0.994 \\
\hline SD EEC & 0.043 & 0.051 & 0.041 & 0.033 & 0.039 & 0.028 \\
\hline$t / p$ & $-3.4 / 0.006$ & & $-3.19 / 0.002$ & & $-0.81 / 0.42$ & \\
\hline
\end{tabular}

manner, it can be concluded that the charging ratio between heavy scrap on one side and sheet metal on the other side influences the EAF's EEC. Statistical differences for special steel grade are not significant, which is most likely due to low number of samples used to perform the analysis, and due to very specific EAF operation to obtain these grades.

Observing Fig. 6, it can be seen that substantial EEC deviations between the minimal and the maximal standard deviations appear within the same cluster, i.e., 0.056 (6\% difference in the best case scenario (special steel, cluster 2 ) and 0.102 (12\% difference) in the worst case scenario (electrical steel). If these percentages are scaled to a typical EAF consumption of $450 \mathrm{kWh} / \mathrm{ton}$, they sum up to $27 \mathrm{kWh} /$ ton and $54 \mathrm{kWh} /$ ton difference, respectively, within the same grade group with similar basket charging, which is a very broad interval of EEC dispersion.

Therefore, further analysis of charging in separate clusters is performed, trying to explain the differences in EEC within the same cluster. Figure 6 shows the means and standard deviations of the charged scrap weights for all three steel grades and for each cluster (clusters 1-lower EEC; clusters 2-higher EEC). In each cluster, the heats are further divided into two groups, i.e., the heats with higher and the heats with lower EECs. Furthermore, for each group, means and SDs for charged scrap weights are calculated. Figure 7 shows the differences in charging weights between the heats with higher and the heats with lower EECs within the same clusters.

As can be seen in Fig. 7, the differences in charging between the heats with higher and the heats with lower EEC within the same clusters are not as evident as in Figs. 5 and 6, which is expected, as the heats contained in each cluster have already been clustered once, depending on the charged scrap types and weights. Whether, in Fig. 5, the heats with higher heavy scrap amount exhibited higher EEC in comparison to the heats with higher sheet metal amount, in Fig. 7, i.e., the charged amounts
Fig. 7 Differences in mean weights and SDs between the heats with higher (dark gray) and the heats with lower (light gray) EEC within the same clusters for all steel targets. a Electrical steels; b structural steels; c special steels

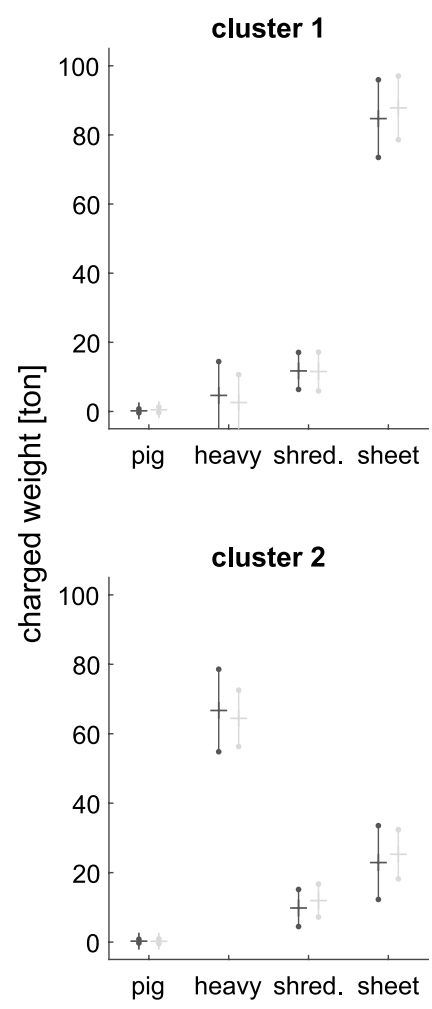

(a)

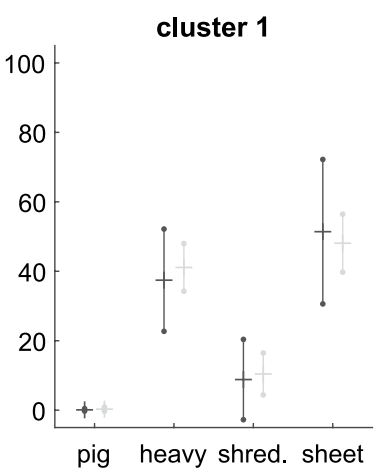

cluster 2

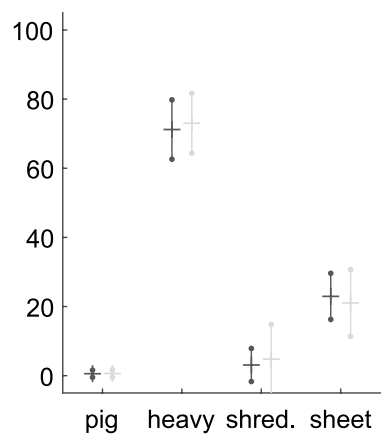

(b)

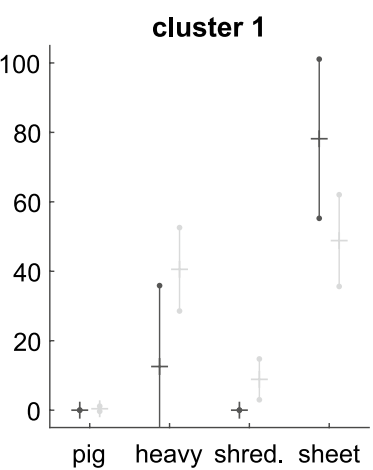

cluster 2

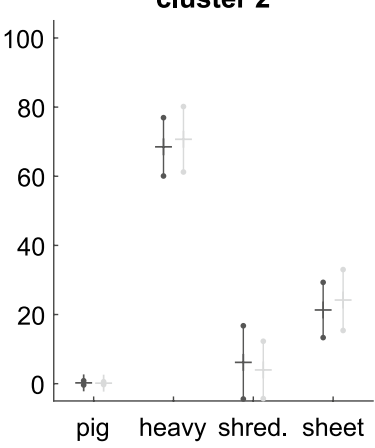

(c) 
of heavy scrap and sheet metal within the same cluster do not follow this pattern. Although some differences in weights of separate scraps are still visible, other conclusions cannot be drawn. To rule out the influence of hot heel, which is not considered in the calculations and varies between the heats, differences in charged weights and obtained EECs are calculated. The differences in charged weight and differences in EECs are calculated for each cluster in order to rule out that fluctuations in EECs are a consequence of fluctuating hot-heel amount.

Observing Table 2, it can be seen that the relative differences in charging weights and the relative differences in EECs for separate clusters are not equal, which to some extent proves that those differences do not arise due to different hot-heel amounts. Furthermore, relative differences in charged weights are rather low, i.e., $2 \%$ in average; therefore, differences in hot-heel amount of such value (absolute) cannot lead to EEC differences as displayed in Table 2, i.e., $14.2 \%$ in average. If this percentage is scaled to a typical EAF consumption of $450 \mathrm{kWh} /$ ton, this leads to more than $60 \mathrm{kWh} /$ ton difference within the same cluster.

Considering the results shown in Fig. 7 and Table 2, further analysis of the EAF actuation is performed in the next section to identify some other possible reasons for EEC fluctuations within the same clusters.

\section{The Influence of Carbon and Oxygen Addition on EEC}

Since the results revealed relatively large differences in EECs for similarly charged heats with minimal power-off times, the same tapping-temperature range, and which are used to produce the same steel grade, further analysis of the EAF actuation, i.e., carbon and oxygen addition, and their influence on the EEC are performed.

As it is known, carbon and oxygen play an important role in providing both chemical energy and proper slag characteristics, such as basicity and foaminess. The reaction between them is exothermic and leads to formation of either $\mathrm{CO}$ or $\mathrm{CO}_{2}$. Ideally, all available $\mathrm{C}$ and $\mathrm{O}_{2}$ react to form $\mathrm{CO}_{2}$; however, in practice, the reaction between $\mathrm{C}$ and $\mathrm{O}_{2}$ is not complete; therefore, only a part of $\mathrm{C}$ is oxidized to $\mathrm{CO}_{2}$, while the other part is oxidized to $\mathrm{CO}$. Furthermore, $\mathrm{C}$ and $\mathrm{O}_{2}$ are also appearing in other chemical reactions. On the other hand, the ratio between $\mathrm{C}$ and $\mathrm{O}_{2}$ and their onset are of crucial importance for proper energy balance and slag forming. Whether a surplus of $\mathrm{O}_{2}$ is present in the EAF, primarily, over-oxidation of the $\mathrm{Fe}-\mathrm{FeO}$ appears. The oxidation of $\mathrm{Fe}$ is an exothermic reaction, which is favorable from the energy point of view; however, it can lead to improper slag characteristics and lower steel yield. On the other hand, a presence of $\mathrm{C}$ surplus leads to reduction of slag oxides, primarily $\mathrm{FeO}$. The reduction of $\mathrm{FeO}$ is an endothermic reaction, which is undesired from the energy point of view; however, not only it leads to higher steel yield but can also lead to excess endpoint $\mathrm{C}$ content, and again, improper slag characteristics. Therefore, proper balance between $\mathrm{C}$ and $\mathrm{O}_{2}$ is crucial, whether EAF operation, steel yield, and energy consumption are to be kept within their normal boundaries. Therefore, an assessment of $\mathrm{C}$ and $\mathrm{O}_{2}$ actuation in terms of their cumulative values is performed for the heats within the same target and the same cluster but with higher and lower EEC. For both, the heats with higher and the heats with lower EEC, approximate availability of the $\mathrm{O}_{2}$ was calculated to check whether any differences in $\mathrm{C}$ and $\mathrm{O}_{2}$ actuation exist between these two groups. Approximate availability of the $\mathrm{O}_{2}$ was obtained according to the estimation presented in Eq. 1:

$\mathrm{O}_{2-\text { available }}=\mathrm{O}_{2-\text { lance }}-\mathrm{O}_{2-\mathrm{c}}$

where $\mathrm{O}_{2 \text {-available }}$ represents the estimated $\mathrm{O}_{2}$ availability, $\mathrm{O}_{2 \text {-lance }}$ represents the amounts of lanced $\mathrm{O}_{2}$, and $\mathrm{O}_{2-\mathrm{C}}$ represents the amount of $\mathrm{O}_{2}$ needed to oxidize the available $\mathrm{C}$. Furthermore, $\mathrm{O}_{2-\mathrm{C}}$ is obtained by Eq. 2:

$\mathrm{O}_{2-\mathrm{c}}=\frac{k_{\mathrm{c}}}{\rho \mathrm{O}_{2}}\left(\mathrm{C}_{\text {charged }}+\mathrm{C}_{\text {scrap }}-\mathrm{C}_{\text {endpoint }}\right)$,

where $C_{\text {charged }}, C_{\text {scrap }}$, and $C_{\text {endpoint }}$ represent the amount of $\mathrm{C}$ (charged in baskets and injected during the heat, contained in scrap, and contained in the bath in the end of the heat), $\rho_{\mathrm{O} 2}$ represents the density of $\mathrm{O}_{2}$ and $k_{\mathrm{C}}$ represents the coefficient, which defines the ratio of masses between $\mathrm{O}_{2}$ and $\mathrm{C}$ and further defines how much $\mathrm{C}$ is oxidized to $\mathrm{CO}$ and how much to $\mathrm{CO}_{2} . k_{C}$ can be obtained according to Eq. 3:

$k_{\mathrm{c}}=2.66 \%_{\mathrm{co}_{2}}+1.33 \%_{\mathrm{co}}$,

where $\%_{\mathrm{CO} 2}$ and $\%_{\mathrm{CO}}$ are set to 0.35 and 0.65 , respectively, meaning that it is assumed that $35 \%$ of the $\mathrm{C}$ is oxidized to $\mathrm{CO}_{2}$, and $65 \%$ to $\mathrm{CO}$, and 2.66 and 1.33 represent the amounts of $\mathrm{O}_{2}$ in $\mathrm{kg}$ needed to oxidize $1 \mathrm{~kg}$ of $\mathrm{C}$ to $\mathrm{CO}_{2}$ and $\mathrm{CO}$, respectively.

Equation 1 calculates approximate $\mathrm{O}_{2}$ availability according to the added $\mathrm{C}$ (charged in baskets, injected during the EAF
Table 2 Relative differences in charged weights and EECs within the clusters when comparing heats with higher and lower EEC

\begin{tabular}{|c|c|c|c|c|c|c|}
\hline \multirow{2}{*}{$\begin{array}{l}\text { Target } \\
\text { Cluster }\end{array}$} & \multicolumn{2}{|c|}{ Electrical } & \multicolumn{2}{|c|}{ Structural } & \multicolumn{2}{|c|}{ Special } \\
\hline & 1 & 2 & 1 & 2 & 1 & 2 \\
\hline Weight difference $(\%)$ & 1.35 & 1.56 & 2.47 & 0.96 & 1.68 & 3.96 \\
\hline EEC difference (\%) & 13.2 & 13.5 & 12.8 & 11.7 & 12.0 & 22.1 \\
\hline
\end{tabular}


operation, and contained in scrap). The equation is intended to approximately estimate, whether the ratio between the added $\mathrm{C}$ and $\mathrm{O}_{2}$ follows the scenario, where all $\mathrm{C}$ is oxidized to either $\mathrm{CO}$ or $\mathrm{CO}_{2}$. The obtained $\mathrm{O}_{2}$ availability shows whether the balance between both added elements is near the ideal ratio or whether one of them is in surplus, leading to, e.g., the oxidation of $\mathrm{Fe}$ and others or to the reduction of $\mathrm{FeO}$ and others. At this point, it needs to be emphasized that the proposed calculations are rough, since there are also other phenomena, which affect the reactions of $\mathrm{C}$ and $\mathrm{O}_{2}$. Nonetheless, Eq. 1 can reveal some useful information about the $\mathrm{C}$-to- $\mathrm{O} 2$ ratio in the EAF, despite not in any manner absolutely accurate in either relative or absolute unit measures.

Figures 8,9 , and 10 show the differences in added amounts of $\mathrm{C}$ and $\mathrm{O}_{2}$ for each produced steel grade, each cluster (according to the clustering pattern shown in Fig. 7), and for the heats with higher and lower EEC within each of these clusters. Furthermore, the figures also show the calculated $\mathrm{O}_{2}$ availability, according to Eq. 1, for the heats with higher and the heats with lower EEC within the same clusters.
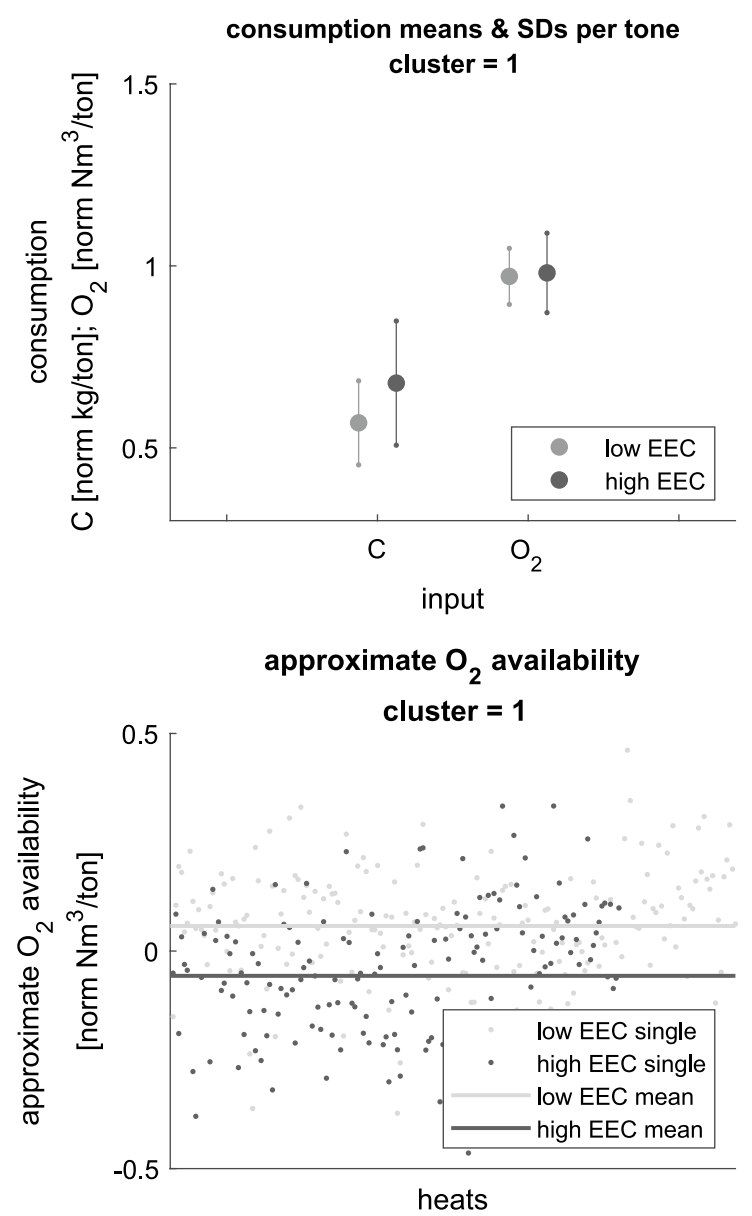

As can be seen in Figs. 8, 9, and 10, the most visible difference is in the amount of added $\mathrm{C}$ (added during melting and contained in scrap), as the heats with higher EECs have significantly higher amount of available $\mathrm{C}$ per ton of steel. In almost all cases, the difference in $\mathrm{O}_{2}$ addition is negligible, except at the second cluster of special steel target, which is most likely a consequence of small number of samples. When the higher amount of $\mathrm{C}$, either added or contained in scrap, is present in the EAF, a higher amount of $\mathrm{O}_{2}$ should be lanced to oxidize the available $\mathrm{C}$ to either $\mathrm{CO}$ or $\mathrm{CO}_{2}$. Otherwise, less chemical energy is provided from $\mathrm{C}$ oxidation, as well as an endothermic reduction of $\mathrm{FeO}$ appears, which leads to a loss of energy and possibly poorer slag characteristics.

Furthermore, as shown in the lower panels of Figs. 8, 9, and 10, the heats with lower EEC have higher $\mathrm{O}_{2}$ availability. This denotes that more $\mathrm{O}_{2}$ is available to oxidize the $\mathrm{C}$ contained in the bath, thus, maintaining a more optimal ratio between them and avoiding either the over-oxidation of $\mathrm{Fe}$ or the reduction of $\mathrm{FeO}$. On the other hand, heats with higher EEC have lower $\mathrm{O}_{2}$ availability, meaning that less $\mathrm{O}_{2}$
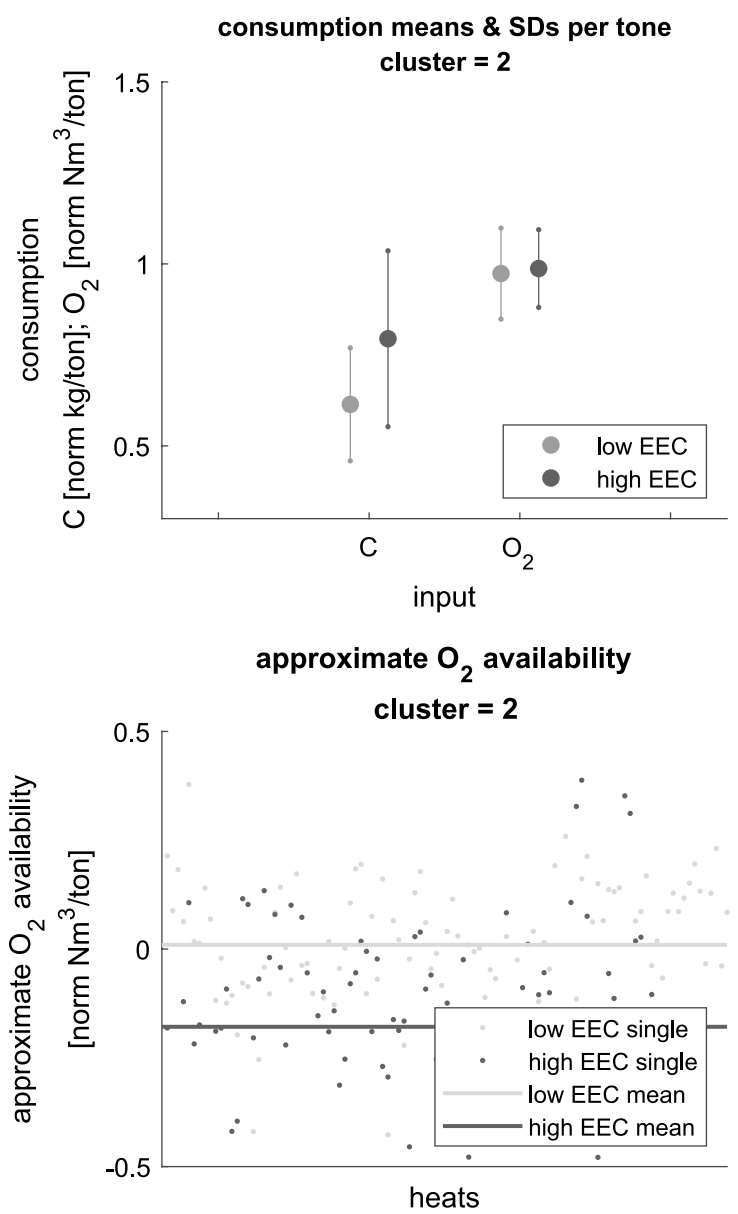

Fig. 8 Comparison of the heats with higher and lower EEC for the electrical steel and clusters 1 and 2. Upper panel: normalized differences in added $\mathrm{C}$ and $\mathrm{O}_{2}$ amounts. Lower panel: normalized differences in $\mathrm{O}_{2}$ availability (single heat and mean value) 

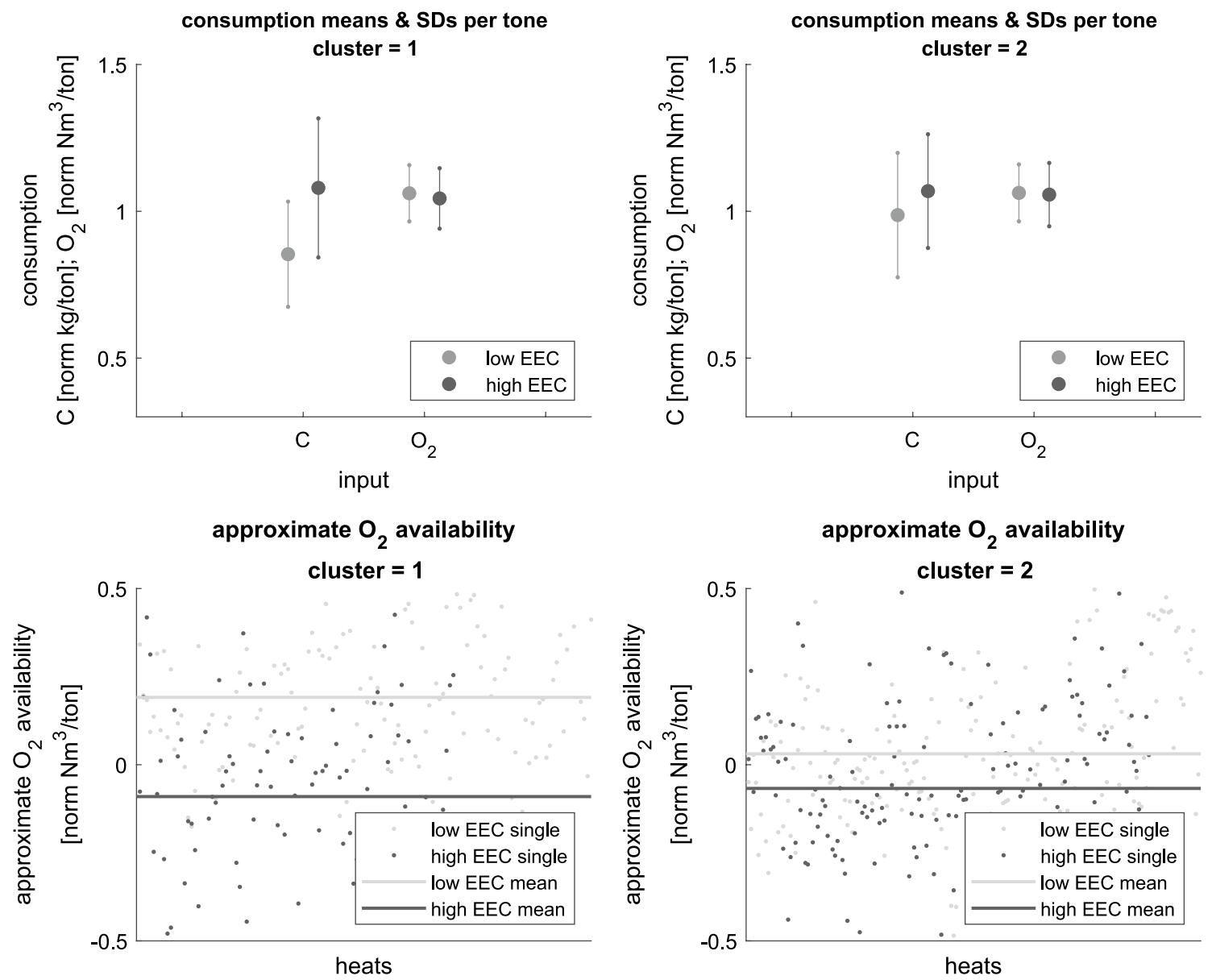

Fig. 9 Comparison of the heats with higher and lower EEC for the structural steel and clusters 1 and 2. Upper panel: normalized differences in added $\mathrm{C}$ and $\mathrm{O}_{2}$ amounts. Lower panel: normalized differences in $\mathrm{O}_{2}$ availability (single heat and mean value)

is available and that its amount could be insufficient for complete oxidation of the available $\mathrm{C}$ in the bath, thus, leading to a surplus of $\mathrm{C}$ and to the loss of energy due to the reduced $\mathrm{C}$ oxidation and the increased $\mathrm{FeO}$ reduction. Estimated values of $\mathrm{O}_{2}$ availability are given in Table 3 in a normalized form.

Given the results in Figs. 8, 9, and 10 and in Table 3, it can be concluded that the ratio between $\mathrm{C}$ and $\mathrm{O}_{2}$ influences the overall EAF energy balance, as the excess amount of $\mathrm{C}$ leads to suboptimal operation of the EAF, causing higher EEC. This conclusion also partially explains the differences in EECs between different steel targets as presented in Fig. 6 . This statement can be supported by the results presented in Fig. 11, which shows the dependency of EEC on $\mathrm{O}_{2}$ availability for each steel grade, clearly showing the decreasing EEC trend with the increasing $\mathrm{O}_{2}$ availability.

At this point, it has to be mentioned that the calculated ratio estimations presented in this section are approximate; however, the study has shown that there is a notable relation between the $\mathrm{C}$-to-O2 ratio, the $\mathrm{C}$ amount alone, and the consequent EEC; therefore, explaining some, but definitely not all, of the fluctuations in the EAF's EEC between similarly charged heats.

These findings can be used to estimate the more optimal C-to-O2 ratio during the EAF operation, leading to lower EECs, and also reducing the role of the operator's experience in the EAF operation. Moreover, other findings, such as the influence of tapping temperature and charging, can also be used to prepare more optimal charging plans and melting programs, intended to lower the EAFs EEC.

\section{Discussion}

In the presented study, a relatively simple statistical analysis, using historical EAF data is performed, intended to determine the crucial factors affecting the EAF's EEC. It is known that the EAF process exhibits significant fluctuations in its EEC, as well as other KPIs, which can be deterministically explained only to a certain extent. Furthermore, it is hard to determine the exact relations between the influential factors and the EEC. In this regard, the paper focuses on 

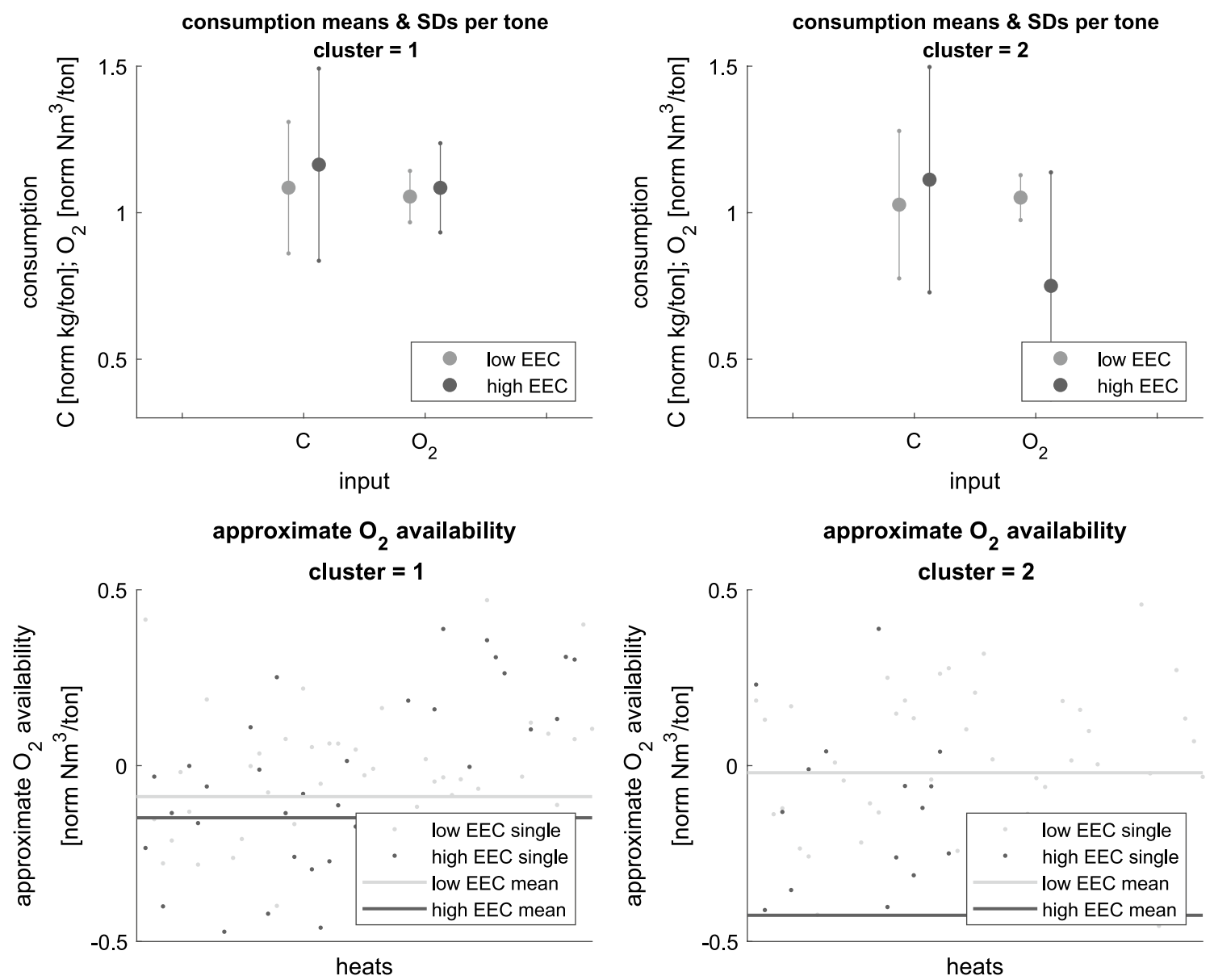

Fig. 10 Comparison of the heats with higher and lower EEC for the special steel and clusters 1 and 2. Upper panel: normalized differences in added $\mathrm{C}$ and $\mathrm{O}_{2}$ amounts. Lower panel: normalized differences in $\mathrm{O}_{2}$ availability (single heat and mean value)

Table 3 Mean normalized $\mathrm{O}_{2}$ availabilities in norm $\mathrm{Nm}^{3} /$ ton for the heats with higher and lower EEC

\begin{tabular}{|c|c|c|c|c|c|c|}
\hline \multirow{2}{*}{$\begin{array}{l}\text { Target } \\
\text { Cluster }\end{array}$} & \multicolumn{2}{|l|}{ Electrical } & \multicolumn{2}{|c|}{ Structural } & \multicolumn{2}{|l|}{ Special } \\
\hline & 1 & 2 & 1 & 2 & 1 & 2 \\
\hline Low EEC $\mathrm{O}_{2}$ availability & 0.057 & 0.001 & 0.191 & 0.031 & -0.088 & -0.020 \\
\hline High EEC $\mathrm{O}_{2}$ availability & -0.057 & -0.179 & -0.090 & -0.067 & -0.148 & -0.426 \\
\hline
\end{tabular}

some additional possible reasons for EEC fluctuations when producing equal steel grades with similar scrap charging patterns. During the study, an interesting relation between $\mathrm{C}$ addition, $\mathrm{O}_{2}$ lancing, and EEC was observed. As has been shown, a relatively strong dependence exists between the $\mathrm{O}_{2}$ availability (or the $\mathrm{C}$-to- $\mathrm{O} 2$ ratio) and the overall EEC, as the heats with higher $\mathrm{O}_{2}$ availability tend to have lower EEC, while on the other hand, the heats with lower $\mathrm{O}_{2}$ availability tend to have higher EEC. There are a few potential reasons that can explain such behavior, i.e., higher EEC can partially be contributed to lower chemical energy release, as the added $\mathrm{C}$ needs to be properly balanced by $\mathrm{O}_{2}$ if their reaction should reach the equilibrium and release all its energy. Whether the amount of $\mathrm{O}_{2}$ is insufficient to oxidize all available $\mathrm{C}$, an increased reduction of the $\mathrm{FeO}$ from the slag can occur, which is an endothermic reaction, meaning that it consumes the energy to proceed. In such manner, the shortage of $\mathrm{O}_{2}$ can have a double effect on the losses of energy, i.e., losing the energy of exothermic reaction between $\mathrm{C}$ and $\mathrm{O}_{2}$, and losing the energy to endothermic reaction between $\mathrm{FeO}$ and $\mathrm{C}$. Knowing that electrical and chemical energies represent up to $60 \%$ and up to $25 \%$ of the total energy input, respectively, such situation is completely possible. Another, yet less feasible phenomenon from the shortage of $\mathrm{O}_{2}$ is a reduction of too much $\mathrm{FeO}$ from the slag, which can also have a negative effect on the energy balance of an EAF. It is well known that optimal slag foaming is achieved in a relatively narrow interval of $\mathrm{FeO}$ percentages, 
Fig. 11 The influence of $\mathrm{O}_{2}$ availability on the EEC for each steel grade. a Electrical steels; $\mathbf{b}$ structural steels; c special steels

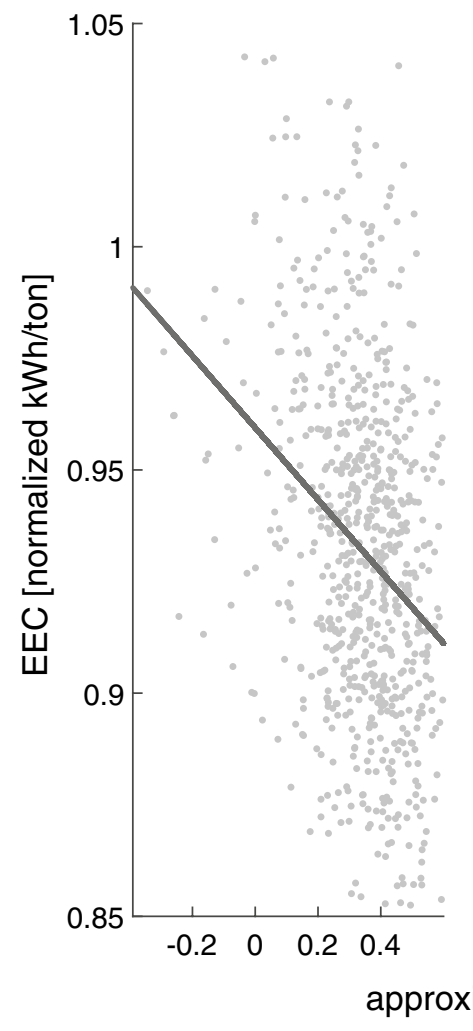

(a)
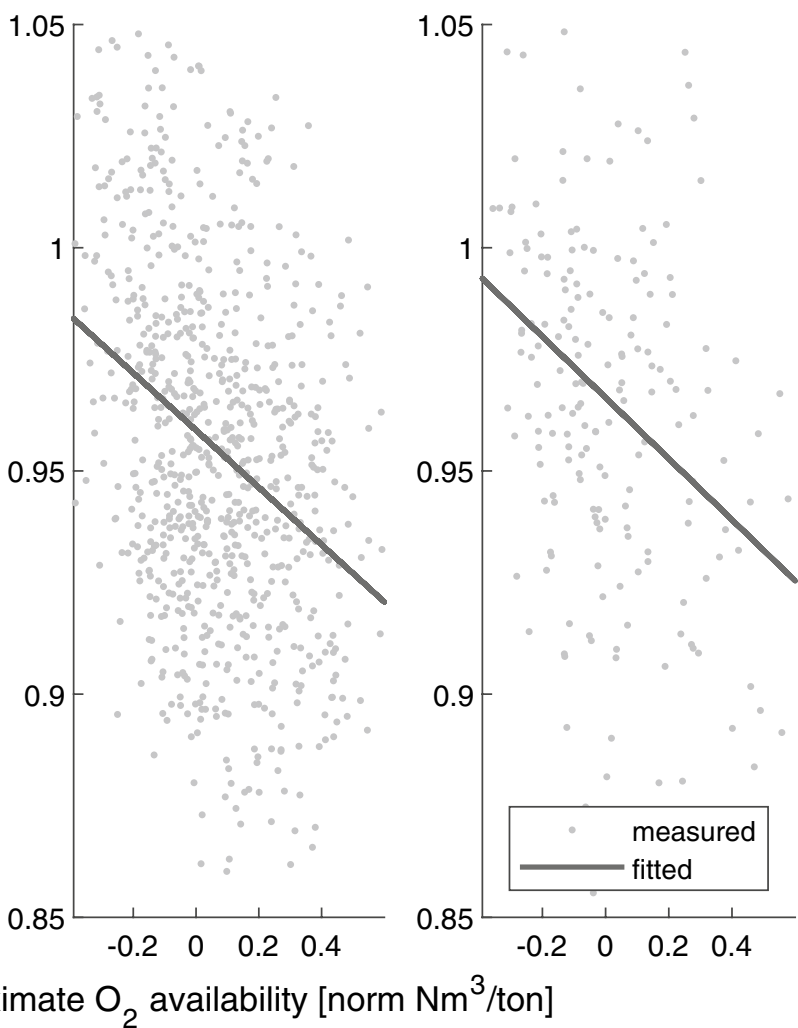

(c) i.e., from approximately 20 to $40 \%$. Whether the $\mathrm{FeO}$ content is outside the prescribed percentage interval, a significant drop in slag foaming index appears, meaning that slag height could become insufficient to cover the electric arcs. In such case, the radiative energy, which would otherwise be captured by the slag and partially transferred to the bath, is lost to other furnace surfaces, such as the roof and the watercooled panels. This can explain some, although not all, reasons for relatively large fluctuations when producing similar steel grades, with similarly charged scrap and similar bath tapping temperature. Besides those, other potential reasons that cause fluctuations in the EAFs EEC could also be scrap mixtures with particularly large pieces, scrap distribution at charging, improper lance positioning, etc.

Besides the identification of some of the possible factors causing EEC fluctuations, the proposed study can also be useful for the estimation of the EEC for a certain heat, as well as for some basic process optimization. As can be seen from the presented results, using such approach, it is possible to estimate an approximate endpoint EEC, with approximately $4 \%$ error margin, considering the charged scrap types and weight, tapping temperature, and the added carbon and oxygen. Since the proposed calculations are computationally light, they can be used to obtain the estimation of the EEC for a certain heat in advance, prior to its processing. Such calculations can be useful for the operators, as it is possible to verify several scenarios (charging weights, tapping temperature, and $\mathrm{C}$ and $\mathrm{O}_{2}$ addition) in terms of the needed electrical energy to process a certain heat. Furthermore, the methodology also allows to determine more optimal charging plans, i.e., charging scrap mixes, which result in lower EEC, as well as a more optimal determination of the carbonto-oxygen ratio, i.e., adding both in an approximate ratio close to the estimated ideal scenario.

\section{Conclusion}

In the presented study, the influence of EAF charging, tapping temperature, and $\mathrm{C}$ and $\mathrm{O}_{2}$ addition on the EAF's EEC was examined. The influence of the charging and the tapping temperature on the EEC is undisputed and has already been proved in other studies; however, the balance between the added $\mathrm{C}$ and $\mathrm{O}_{2}$ is usually neglected in such analyses. As has been shown, total values of added $\mathrm{C}$ and lanced $\mathrm{O}_{2}$ could also have an important effect on the EAF's EEC, which can partially explain the fluctuations in EECs between the heats, which are otherwise similarly charged, have similar tapping-temperature range, and are intended to produce equal steel grades. As has been shown, achieving a proper ratio between the $\mathrm{C}$ and the $\mathrm{O}_{2}$ should lead to lower EEC, which is expected, as a surplus of $\mathrm{C}$ can lead to incomplete 
chemical reactions, as well as to poorer slag characteristics, both leading to increased EEC. In this manner, modifications to the existent EAF actuation can be performed, aiming to improve the EAF's EEC as well as its other KPIs.

Acknowledgements The work presented in this paper is funded by the European Union's Horizon 2020 research and innovation programme, SPIRE initiative, under Grant agreement no. 869815, project INEVITABLE ("Optimization and performance improving in metal industry by digital technologies").

\section{Declarations}

Conflict of interest On behalf of all authors, the corresponding author states that there is no conflict of interest.

Open Access This article is licensed under a Creative Commons Attribution 4.0 International License, which permits use, sharing, adaptation, distribution and reproduction in any medium or format, as long as you give appropriate credit to the original author(s) and the source, provide a link to the Creative Commons licence, and indicate if changes were made. The images or other third party material in this article are included in the article's Creative Commons licence, unless indicated otherwise in a credit line to the material. If material is not included in the article's Creative Commons licence and your intended use is not permitted by statutory regulation or exceeds the permitted use, you will need to obtain permission directly from the copyright holder. To view a copy of this licence, visit http://creativecommons.org/licenses/by/4.0/.

\section{References}

1. Barker KJ, Blumenschein CD, Bowman B, Chan AH, Choulet RJ, Doran DJ (1998) Overview of steelmaking processes and their development. In: Fruehan RJ (ed) The making, shaping and treating of steel. The AISE Steel Foundation, Pittsburgh

2. Lee B, Sohn I (2014) Review of innovative energy savings technology for the electric arc furnace. JOM 66(9):1581-1594. https:// doi.org/10.1007/s11837-014-1092-y

3. Gandt K, Meier T, Echterhof T, Pfeifer H (2016) Heat recovery from EAF off-gas for steam generation: analytical exergy study of a sample EAF batch. Ironmak Steelmak 43(8):1-7. https://doi. org/10.1080/03019233.2016.1155812

4. Barati M, Esfahani S, Utigard TA (2011) Energy recovery from high temperature slags. Energy 36(9):5440-5449. https://doi.org/ 10.1016/j.energy.2011.07.007

5. Kirschen M, Risonarta V, Pfeifer H (2008) Energy efficiency and the influence of gas burners to the energy related carbon dioxide emissions of electric arc furnaces in steel industry. Energy 34(9):1065-1072. https://doi.org/10.1016/j.energy.2009.04.015

6. Lee B, Ryu JW, Sohn I (2014) Effect of hot metal utilization on the steelmaking process parameters in the electric arc furnace. Steel Res Int 86(3):302-309. https://doi.org/10.1002/srin.201400157

7. Bisio G, Rubatto G, Martini R (2000) Heat transfer, energy saving and pollution control in UHP electric-arc furnaces. Energy 25(11):1047-1066. https://doi.org/10.1016/S0360-5442(00) $00037-2$
8. Bekker JG, Craig IK, Pistorius PC (2000) Model predictive control of an electric arc furnace off-gas process. Control Eng Pract 8(4):445-455. https://doi.org/10.1016/S0967-0661(99)00163-X

9. Oosthuizen DJ, Craig IK, Pistorius PC (2004) Economic evaluation and design of an electric arc furnace controller based on economic objectives. Control Eng Pract 12(3):253-265. https:// doi.org/10.1016/S0967-0661(03)00078-9

10. MacRosty RDM, Swartz CLE (2007) Dynamic optimization of electric arc furnace operation. AIChE J 53(3):640-653. https:// doi.org/10.1002/aic.11104

11. MacRosty RDM, Swartz CLE (2005) Dynamic modeling of an industrial electric arc furnace. Ind Eng Chem Res 44(31):80678083. https://doi.org/10.1021/ie050101b

12. Saboohi Y, Fathi A, Škrjanc I, Logar V (2019) Optimization of the electric arc furnace process. IEEE Trans Ind Electron 66(10):8030-8039. https://doi.org/10.1109/TIE.2018.2883247

13. León-Munizaga N, Aguirre-Munizaga M, Lagos-Ortiz K, Del Cioppo-Morstadt J (2020) Prediction of energy consumption in an electric arc furnace using Weka. Technologies and innovation, CITI2020. Communications in computer and information science, vol 1309. Springer, Cham, pp 58-70

14. Chen C, Liu Y, Kumar M, Qin J (2018) Energy consumption modelling using deep learning technique - a case study of EAF. Proc CIRP 72:1063-1068. https://doi.org/10.1016/j.procir.2018.03.095

15. Kovačič M, Stopar K, Vertnik R, Sarler B (2019) Comprehensive electric arc furnace electric energy consumption modelling: a pilot study. Energies 12(11):2142. https://doi.org/10.3390/en12112142

16. Carlsson L, Samuelsson P, Jönsson P (2019) Predicting the electrical energy consumption of electric arc furnaces using statistical modelling. Metals 9(9):959. https://doi.org/10.3390/met9090959

17. Köhle S (1992) Enflussgrößen des elektrischen Energieverbrauchs und des Elektrodenverbrauchs von Lichtbogenöfen. Stahl un Eisen 112(11):59-67

18. Pfeifer H, Kirschen M (2002) Thermodynamic analysis of EAF energy efficiency and comparison with a statistical model of electric energy demand. Proc. 7th European electric steelmaking conference, Venice, Italy, p 1413-1428

19. Gajić D, Savić-Gajić I, Savić I, Georgieva O, Di Gennaro S (2016) Modelling of electrical energy consumption in an electric arc furnace using artificial neural networks. Energy 108:132-139. https://doi.org/10.1016/j.energy.2015.07.068

20. Matino I, Colla V, Baragiola S (2017) Electric energy consumption and environmental impact in unconventional EAF steelmaking scenarios. Energy Procedia 105:3636-3641. https://doi.org/ 10.1016/j.egypro.2017.03.839

21. Haupt M, Vadenbo C, Zeltner C, Hellweg S (2017) Influence of input-scrap quality on the environmental impact of secondary steel production. J Ind Ecol 21(2):391-401. https://doi.org/10. $1111 /$ jiec. 12439

22. Sandberg E (2005) Energy and scrap optimization of electric arc furnaces by statistical analysis of process data. Luleå University of Technology, Sweden

23. Pesamosca A, Patrizio D (2016) Latest trends in EAF optimization of scrap-based melting process: balancing chemical and electrical energy input for competitive and sustainable steelmaking. Proc. 47 Seminário de Aciaria-Internacional, ABM Week, Rio de Janeiro, Brazil, p 169-182

Publisher's Note Springer Nature remains neutral with regard to jurisdictional claims in published maps and institutional affiliations. 